\title{
An ancestor of the stereotactic atlases: the Tabulae Anatomicae of Bartolomeo Eustachio
}

\author{
Alessandro Dario, MD, ${ }^{1}$ Giuseppe Ottavio Armocida, MD, ${ }^{2}$ and Davide Locatelli, MD1 \\ ${ }^{1}$ Neurosurgical Clinic, ASST Settelaghi; and 2Department of Medicine and Public Health, Insubria University, Varese, Italy
}

The authors report the history of the Tabulae Anatomicae of Bartolomeo Eustachio (ca. 1510-1574). In the tables, the anatomical illustrations were drawn inside a numerical frame, with pairs of numbers on the $y$ - and $x$-axes to identify single anatomical details in the reference table. The measures and the references could be calculated using the graduated margins divided by 5 units for each the $\mathrm{x}$-axis and $\mathrm{y}$-axis. The Tabulae Anatomicae can be considered a precursor to modern anatomical reference systems that are the basis of studies on cerebral localization mainly used for stereotactic procedures.

https://thejns.org/doi/abs/10.3171/2019.6.FOCUS19339

KEYWORDS stereotactic atlas; Bartolomeo Eustachio; cerebral localization

$\mathrm{T}$ $\mathrm{HE}$ basis of anatomical localization and function is the precise position in the space of the anatomical structures involved. Moreover, the boundaries of the space occupied by the localization of a nervous function must be measurable. For this purpose, a spatial representation of the localization described is necessary. Localization has its practical and visible basis on atlases or anatomical maps. Usually, maps must be graduated or scaled with a reference system, especially if the atlas is used for stereotactic operations. ${ }^{17}$ In addition, modern functional imaging techniques rely on atlases to locate an anatomical formation or function and its dimensions in the space. , $^{3,10,16}$

Although the brain localization model that links specific functions to specific and exactly localized areas is not as valid today and has been improved by a model based on a dense functional interconnection, ${ }^{13,16}$ it is true that a nervous function has a prevalent base in a certain point of the cortex or the subcortical nuclei that is well represented by anatomical or functional maps of the brain. We have found that the Tabulae Anatomicae of Bartolomeo Eustachio can be considered an ancestor of modern stereotactic brain atlases.

\section{History of the Tabulae Anatomicae}

Bartolomeo Eustachio was born ca. 1510 in San Severino Marche, a city near Macerata, Italy. In 1539, the city of San Severino appointed Bartolomeo doctor of the city with the title of Scientist Most Excellent (Physicus Eccellentissimus)..$^{9}$ In 1530, he was called to Urbino to the court of Duke Guidobaldo as his personal doctor. Here, Eustachio found a sophisticated environment while working at the court of the noble family della Rovere with the greatest intellectuals of the time., ${ }^{9,12}$

In this court, with the help of Federico Commandino (1509-1575), Eustachio devoted himself to the study of Hebrew and Arabic, but above all mathematics and geometry, disciplines he considered indispensable for the correct understanding and reproduction of the "architecture" of the human body, with its method based on abscissas and ordinates (horizontals and verticals). ${ }^{2,12} \mathrm{He}$ was then called to Rome by Cardinal Giulio della Rovere, Guidobaldo's brother, around 1547, as his personal doctor. In Rome, Eustachio became a famous clinician, treating San Filippo Neri (1515-1595) and Carlo Borromeo (1538-1584), and taught at Sapienza University as chair of anatomy from 1555 to 1568.9

While in Rome, he combined the study of medicine with the study of anatomy with the help of his favorite pupil, Pier Matteo Pini. This new system replaced empiricism and the dominant tradition with observation and experimentation. Eustachio's notoriety in Rome led him to become "protomedical" of the Papal State, but it also caused the envy and jealousy of colleagues. ${ }^{12}$ 
He used corpses from the hospitals of Santo Spirito and Consolazione for his dissections. In particular, the latter hospital was dedicated to the treatment of trauma, and Eustachio had extensive conversations with many masters of surgery. 5,12

In 1563-1564, Eustachio gave drawings and text from his investigations on the structure and physiology of the human body to the publisher Vincenzo Luchino in Venice, and they became Opuscula Anatomica, ${ }^{7}$ a collection of 5 treatises concerning the kidneys, the ear (1562), the bones and the movements of the head (1561), the veins, and the teeth (1563).

Eustachio worked for a long time on a more ambitious project on human anatomy, ${ }^{9}$ comprising large anatomical plates and comments in which he discussed statements by Andreas Vesalius (1514-1564), who in 1543 had published the well-illustrated De Humani Corporis Fabrica Libri Septem..$^{20}$

Eustachio disagreed with Vesalius and was a supporter of Galen (129 to ca. 201); in fact, his research was a revision of the anatomy of Galen. ${ }^{12}$ The Roman anatomist in the preface of the Opuscula Anatomica announced the publication of 46 tables engraved on copper accompanied by a treatise in which the views of ancient and modern physicians would be compared with his own anatomical observations. In fact, 8 of these tables, concerning renal anatomy, were published in the Opuscula Anatomica. The 8 published tables were part of the announced editorial project consisting of 46 plates and an explanatory text entitled "De dissensionibus, ac controversiis anatomicis." The plates were drawn by 1552 with the help of Pier Matteo Pini; however, publication of the entire opus was delayed because Eustachio wanted to respond to the criticism raised by the publication of the Opuscula Anatomica. In the Examen ossium et de motu capitis, Eustachio attempted to demonstrate how the anatomy described by Galen was that of the monkey and not that of the man he wanted to illustrate through direct observation of the body. ${ }^{6}$ In Epistola de auditus organo, he expresses the necessity of a careful and rigorous observation of the organs (the ear) and of their functioning in stark contrast with the scarce accuracy of Vesalius. However, due to Eustachio's age, poor health, and death on August 27, 1574, the work was no longer edited. ${ }^{9}$ In his representation of the human body, Eustachio carried out a method never used before for anatomical illustration. His drawings were made inside a numerical frame in which pairs of numbers could identify the single details in the reference table.

According to the will of Eustachio, Matteo Pini should have published the work, but this did not happen, and traces of the tables and text were lost. Thereafter, the work of Eustachio vanished, despite the desperate search to find them. In the 17th century, doctors and anatomists tried to find the anatomical plates of Eustachio in Rome and San Severino, considering their scientific importance. Marcello Malpighi (1628-1694) also participated in the searches without success.

In 1712, Giovanni Maria Lancisi (1654-1720), the doctor of Pope Clemente XI, found the plates and published them in $1714 .{ }^{8}$ There were 47 published tables, including those previously published on renal anatomy; all tables were added to the corpus immediately after the discovery, although it seems that 7 tables were permanently lost. Historians, however, have some doubt as to whether all the tables published by Lancisi were drawn by Eustachio; it appears likely that in addition to Eustachio, the tables were also drawn by other illustrators.

After the first edition, the anatomical tables were kept at the Lancisian Library. ${ }^{9}$

The Tabulae Anatomicae was a publishing success and had several editions (Fig. 1). After some time, a new edition in Italian by Gaetano Petrioli, Roman doctor and physician of the King of Sardinia, using the original tables, was published in 1742 in Rome..$^{15}$ In 1744, the esteemed anatomist Bernard Albinus from Leiden ${ }^{1}$ wrote his own explanatory text to the engravings and made outline copies of each figure so that he could label anatomical details without cluttering up the original images. He also devised a very clever scheme of graphical coordinates along the horizontal and vertical axes of each plate so that he could reference features by anatomical location. Then the original tables were purchased by Andrea Massimini (17271792), surgeon of the Consolazione Roman hospital, for an elegant, commented edition published in $1783 .{ }^{9}$ Since then, the traces of the copper plates have disappeared, and to date we do not know the whereabouts of the originals. Eustachio's comments on the tables have not been found; rather, the comments are those of Lancisi. The research also involves America and the father of neurosurgery and great collector Harvey Cushing (1869-1939). A Florentine antiquarian named Leo Olschki wrote to Cushing and proposed the purchase of a manuscript with anatomical designs and autograph commentary of Eustachio. ${ }^{9}$ Cushing immediately bought the manuscript, but realized that the drawings were copied from the anatomical works of Vesalius and other anatomists, and, above all, the writings were not those of Eustachio. Today, the manuscript is kept in New Haven, Medical Historical Library, Harvey Cushing Collection, n. 9.

The numbers were added to the large plates in the 18th century after their discovery. However, the original text of the tables remained missing until 1972 when Luigi Belloni found a manuscript in the Siena library that included most of the text. ${ }^{9}$ The text treated the human anatomy as a whole and was organized as syngrammata and antigrammata, i.e., quotations from the main work of Vesalius and the subsequent approvals or objections of Eustachio. ${ }^{12}$ The citations of Vesalius (syngrammata) are practically complete, but the observations of Eustachio (antigrammata) are often lacking or incomplete. Unfortunately, the parts of the text about the brain and nerves are not present and are still missing. ${ }^{9}$

The anatomical images in Tabulae Anatomicae were placed within a numerical frame to identify the individual details. In particular, table XVII depicts the brain, the cerebellum, and the spinal cord in 7 drawings, of which 5 are sections of the brain (Fig. 2). In this table, the brain was dissected primarily in the axial plane. In table XVIII, the brain and the spine with nerves are shown (Fig. 3). Next to the tables, there were explanations and descriptions of the figures with relative numbers of reference in the space (Figs. 4 and 5). These anatomical descriptions, however, 


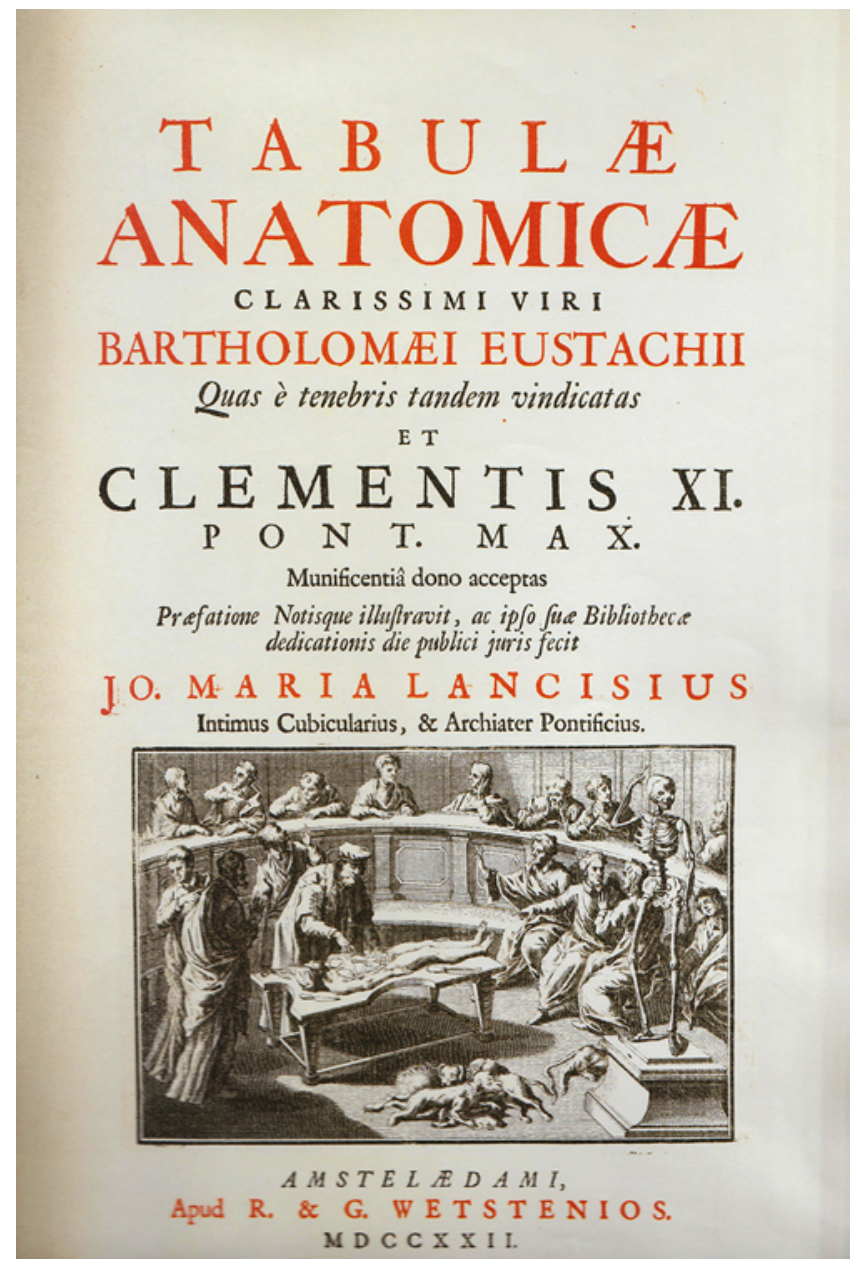

FIG. 1. The frontispiece of the 1722 edition of Tabulae Anatomicae. The etching by Pietro Ghezzi (1674-1755) represents Eustachio dissecting a human corpse in the anatomical theater. From Tabulae Anatomicae Clarissimi Viri Bartholomaei Eustachii Quas è Tenebris Tandem Vindicatis. Amsterdam: R \& G Wetstenios, 1722, public domain. From the collection of Dr. Giuseppe Ottavio Armocida.

are not the original text of Eustachio and were written after the tables' discovery. The measures and the numbers of references could be calculated using the graduated margins (frame) divided by 5 units for each the $\mathrm{x}$-axis and $\mathrm{y}$-axis.

The tables were etched and surrounded by a frame made of wood or metal that was slightly taller than the height of the table. There were 2 different methods for finding in the figures the anatomical details described by Eustachio himself.7 The first method consisted of constructing a strip of paper as large as a finger, whose length corresponds to the short side of the table, of which it must also reproduce the same division in degrees and numbers. The paper strip can run on the longitudinal axis and forms the movable line of the reference system of the $\mathrm{x}$ - and $\mathrm{y}$-axes. The first number in the description of the tables corresponds to the long side of the frame (y-axis), while the second number corresponds to the mobile strip (x-axis) located at the level indicated by the first number; thus, the anatomical detail can easily be found. The second system consists of mak-

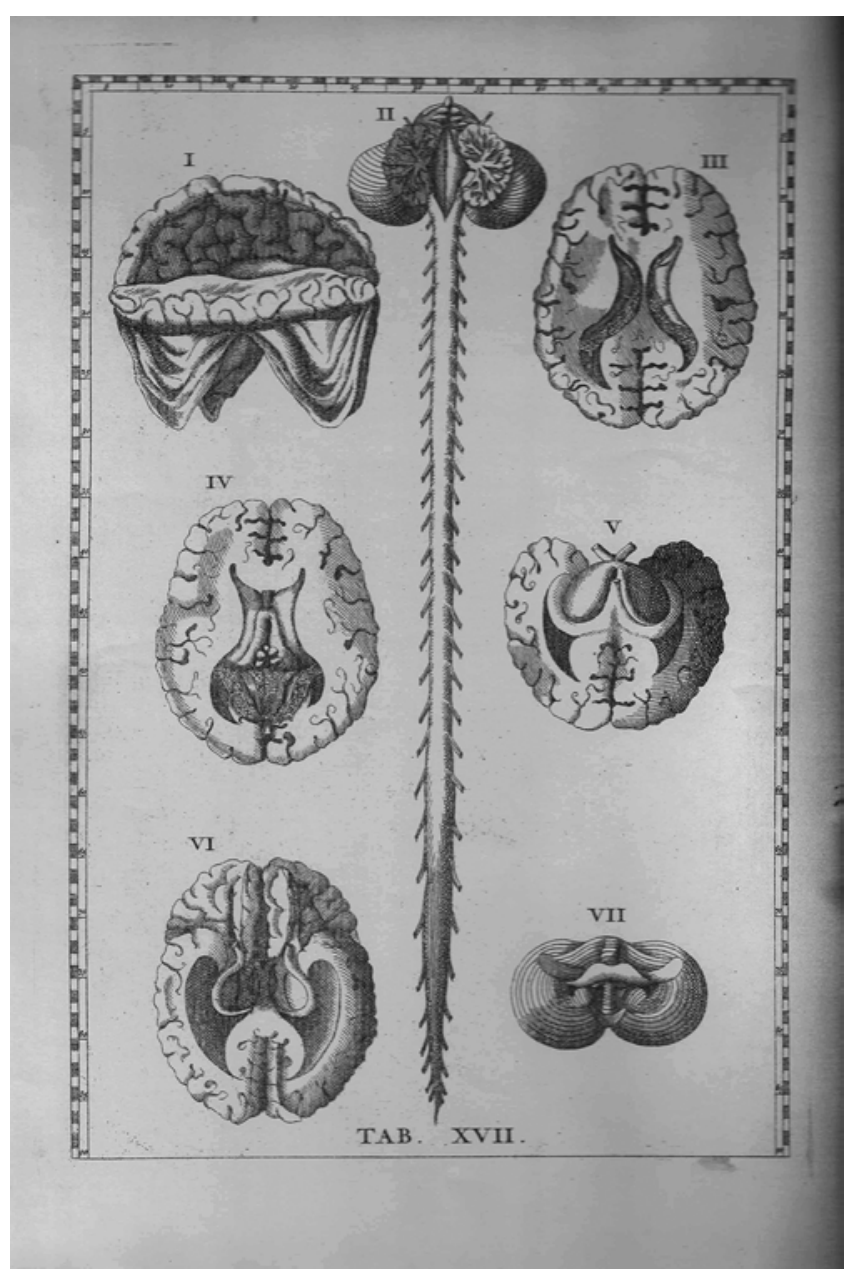

FIG. 2. Table XVII shows the brain and medulla divided in 7 figures. Four of these are axial sections of the brain with details of the deep structures. The table is surrounded by the 2 numbered axes of the coordinate system. From Tabulae Anatomicae Clarissimi Viri Bartholomaei Eustachii Quas è Tenebris Tandem Vindicatis. Amsterdam: R \& G Wetstenios, 1722, public domain.

ing a flat circle with 2 wires: one perpendicular and one horizontal to the circle at a right angle. The circle can be moved so that the 2 wires are in correspondence with the 2 numbers indicated in the text; the searched point corresponds to the intersection of the 2 wires.

\section{Discussion}

The coordinate system constituted an absolute novelty in anatomical illustration, but it cannot be considered an invention of Eustachio; in fact, it is a cartographic instrument that the author himself defined as geometricus gnomon, a graduated frame that identifies coordinates of the places indicated in the captions by latitude and longitude. The instructions for reading the tables provided in De usu tabularum are in direct relation to the method reported by Peter Apian (1501-1552) for reading the Ptolemaic tables in order to find locations of regions or cities. ${ }^{4}$ This system of coordinates was appropriated for anatomical purposes to locate a precise point in an anatomical structure, 


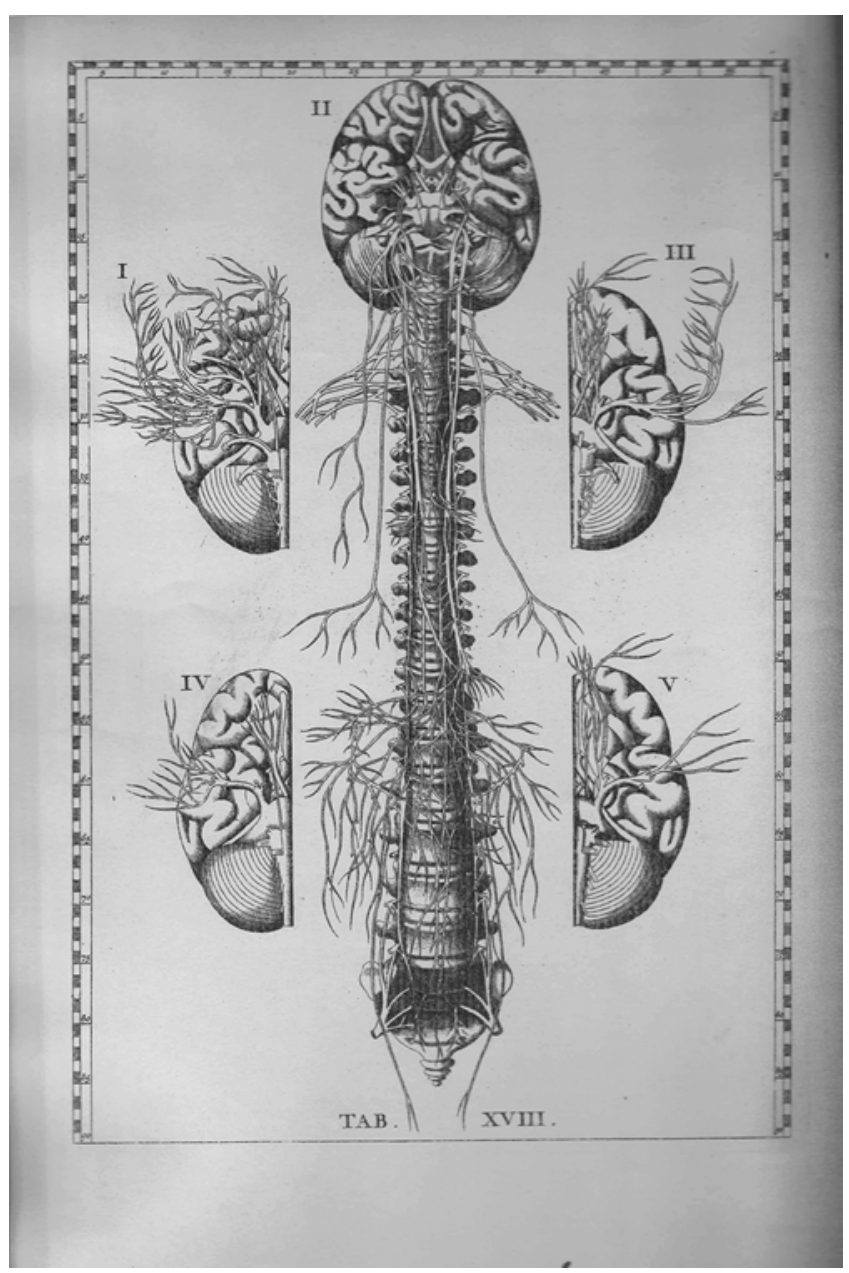

FIG. 3. Table XVIII represents the lower surface of the brain with the cranial nerves and the spine with its nerves and sympathetic nervous system. From Tabulae Anatomicae Clarissimi Viri Bartholomaei Eustachii Quas è Tenebris Tandem Vindicatis. Amsterdam: R \& G Wetstenios, 1722, public domain.

demonstrating the direct relationship between geographical and anatomical knowledge based on the conception of man as a microcosm. ${ }^{2}$ This ancient concept of man as microcosm met a new favor in Renaissance humanistic thought with the interest of its greatest representative, Leonardo da Vinci (1452-1519). Why Eustachio used this system of anatomical representation can be explained by the concept that the author had of anatomy: the representation of the body not as an ideal entity but as a product of a variable nature that requires a system of coordinates to illustrate the specific details. The need to make numerous anatomical observations before producing general considerations with the multiplication of singular images was for Eustachio the only way to represent nature: ${ }^{4}$ the graduated grid was the tool to perform this process. The tables of Eustachio were unfortunately not used during the Renaissance, as they were lost, and Eustachio's method of coordinates was no longer described until modern times with the advent of stereotactic atlases. Obviously, the coordinates could only be used in 2 dimensions, but the precision in the description and location of deep structures of the

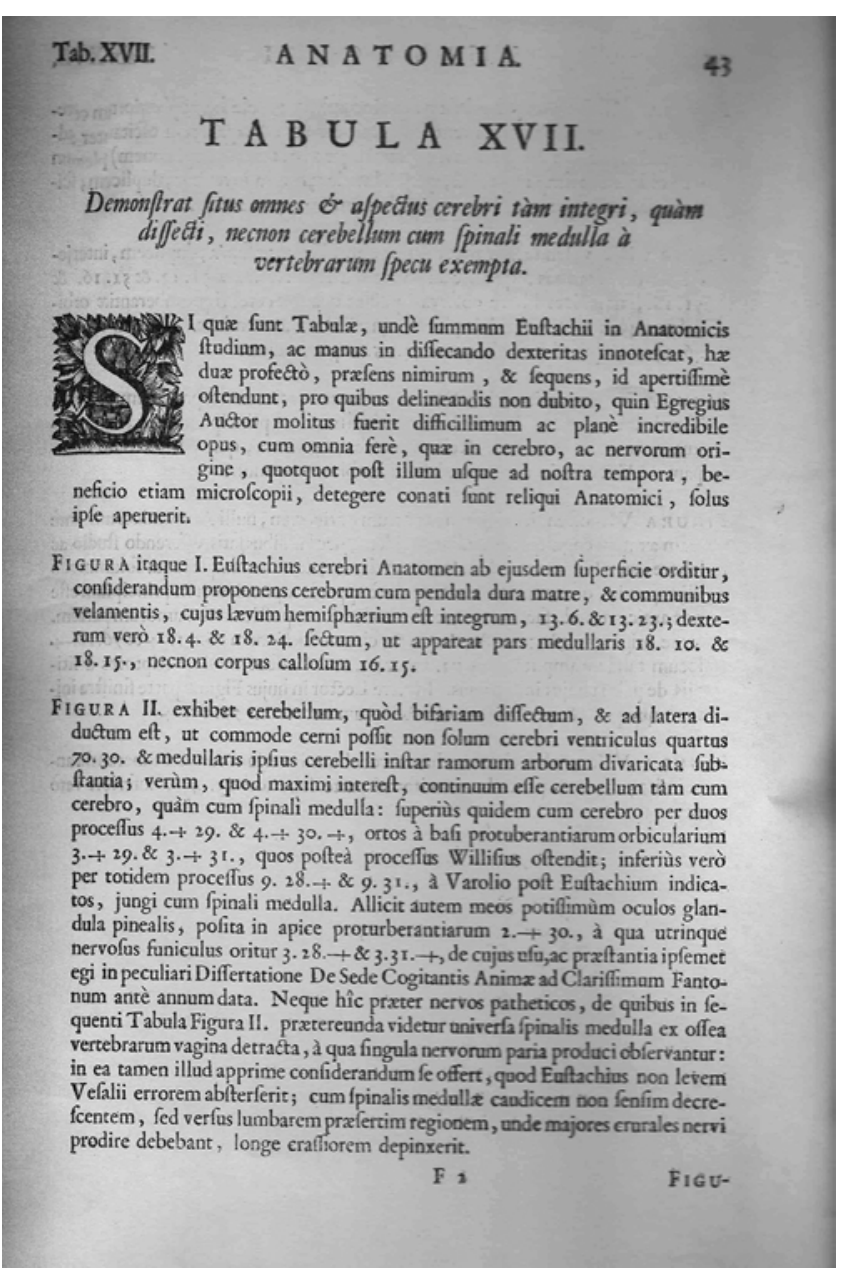

FIG. 4. Explanations and descriptions of the figures with relative numbers of reference in the coordinate system; the first number refers to the $y$-axis and the second number to the x-axis. From Tabulae Anatomicae Clarissimi Viri Bartholomaei Eustachii Quas è Tenebris Tandem Vindicatis. Amsterdam: R \& G Wetstenios, 1722, public domain.

brain (table XVII; figures III, IV, and VI) or other organs in the axial plane had never been described. Moreover, the coordinate system could be used on several close anatomical sections of the same organ. Eustachio had not intended for his atlas to locate specific areas of the brain, but undoubtedly his work can be considered a distant beginning of stereotactic procedures. ${ }^{8}$ Eustachio's tables were not focused only on the brain but on the entire body; however, the brain is the organ that can best be represented by this type of measurement system of mathematical coordinates.

The importance of images in anatomical publications when Eustachio created his plates was well known; in fact, the first anatomical treatise with drawings, titled Commentario, had already been published 30 years before by Mondino di Berengario da Carpi. ${ }^{14}$ In those same years, Vesalius reported the shortcomings of Galenism on the anatomical level, with illustrations that reached excellent levels, as did also those of Leonardo da Vinci, who improved the artistic illustrations of the brain, drawn on the basis of his own dissection. Eustachio's tables XVII and XVIII (Figs. 2 and 3 ), dedicated to the brain and nervous system, are the most 


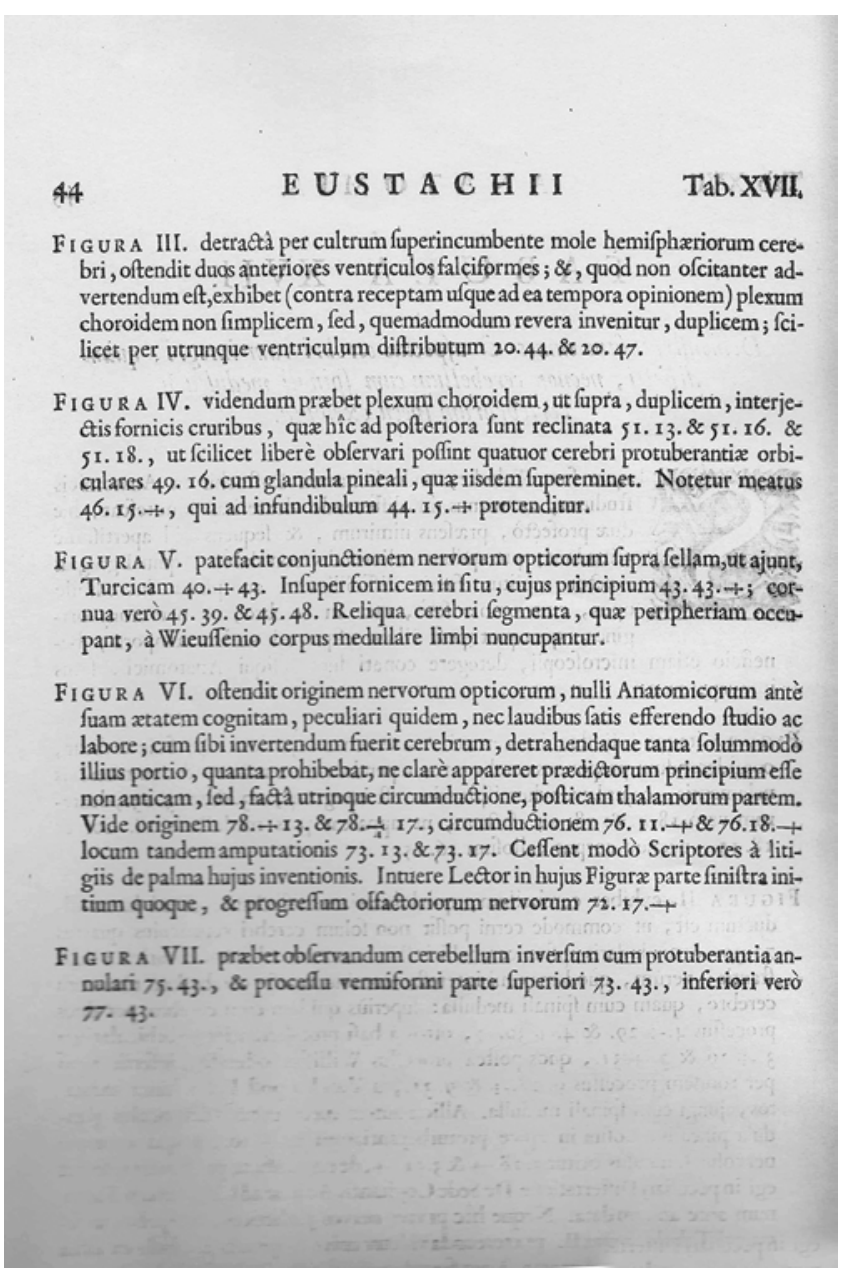

FIG. 5. Explanations and descriptions of table XVII figures: note in the description of figure III the exact centering of the lateral ventricle by coordinates 20.44 and 20.47. From Tabulae Anatomicae Clarissimi Viri Bartholomaei Eustachii Quas è Tenebris Tandem Vindicatis. Amsterdam: R \& G Wetstenios, 1722, public domain.

accurate of the time. If these plates had not been missing for so long, Eustachio would undoubtedly have been considered the founder of anatomy, along with Andreas Vesalius. These tables represented a definite improvement in both anatomical and technical details, compared with the anatomical works of the previous century. The anatomical controversies were heavy indeed; as Eustachio said, "tamen spero non defuturos, qui aequos se mihi judices praebent" (I hope there will be fair judges who offer me [author's transl]). In the woodcut technique of Vesalius' drawings, a precise delineation of the hemispheric convolutions (Fig. 6) is present, while in Eustachio's drawings the cerebral convolutions were not presented very realistically, neither the orbital gyri of the frontal lobe nor convolutions of the temporal lobe (Figs. 2 and 3).

Prior to the drawings of Eustachio and Vesalius, anatomical representation largely ignored the cortex. In anatomical drawings, the cortex often appeared more like a plate of macaroni than the surface of the brain; ${ }^{10,11}$ however, with the drawings of Eustachio and Vesalius, one begins to observe anatomical details more closely resem-

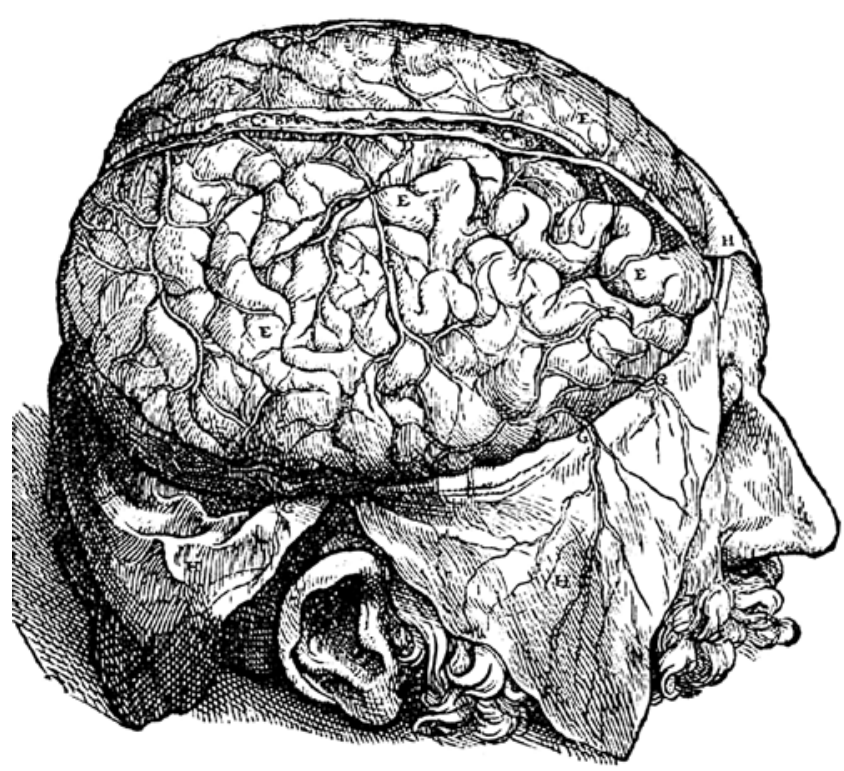

FIG. 6. Vesalius' anatomical drawing of the brain showing exposed convolutions. From Vesalius A: De Humani Corporis Fabrica Libri Septem. Basel: Ioannis Oporini, 1538. From the collection of Dr. Alessandro Dario.

bling the brain, which would improve future anatomical representations, although in the drawings of Larionov ${ }^{18,19}$ on the functional localization of the cortex, it is represented with symmetrical and perpendicular sulci and gyri that recall figures III and IV of Eustachio's table XVII (Fig. 2). In the 19th century, there was much debate regarding the cerebral localization of functions; ${ }^{18}$ the anatomical system of Eustachio could have been helpful in clarifying these locations if it had been available.

Although Eustachio did not directly study the localization of brain function, there is no doubt that his conception of anatomy is a precursor of the modern anatomical reference systems that are the basis of studies on cerebral localization mainly used for stereotactic procedures. Eustachio was a typical man of the Renaissance who combined mathematical sciences with humanism.

\section{References}

1. Albinus BS: Explicatio tabularum anatomicarum Bartholomaei Eustachii, anatomici summi. Accedit tabularum editio nova. Leiden: Langerak \& Verbeeck, 1744

2. Andretta E: Bartolomeo Eustachi, il compasso e la cartografia del corpo umano. Quad Stor 130:93-125, 2009

3. Anthofer J, Steib K, Fellner C, Lange M, Brawanski A, Schlaier J: The variability of atlas-based targets in relation to surrounding major fibre tracts in thalamic deep brain stimulation. Acta Neurochir (Wien) 156:1497-1504, 2014

4. Apian P: Cosmographicae Introduction. Ingolstadt, 1529

5. Eustachi B: Epistola de auditus organo. Rome, 1562

6. Eustachi B: Examen ossium et de motu capitis. Rome, 1561

7. Eustachi B: Opuscula Anatomica. Venice, 1564

8. Eustachi B, Lancisi GM: Tabulae Anatomicae Clarissimi Viri Bartholomaei Eustachii Quas è Tenebris Tandem Vindicatis. Rome: Francisci Gonzagae, 1714

9. Fortuna S: Le Tabulae anatomicae di Bartolomeo Eustachio. Medicina e Chirurgia 64:2913-2916, 2014 
10. Jakab A, Werner B, Piccirelli M, Kovács K, Martin E, Thornton JS, et al: Feasibility of diffusion tractography for the reconstruction of intra-thalamic and cerebello-thalamic targets for functional neurosurgery: a multi-vendor pilot study in four subjects. Front Neuroanat 10:76, 2016

11. Karenberg A: Cerebral localization in the eighteenth century-an overview. J Hist Neurosci 18:248-253, 2009

12. Muccillo M. Dizionario biografico degli Italiani. Rome: Istituto della Enciclopedia Italiana, 1993, Vol 43

13. Nazarova M, Blagovechtchenski E: Modern brain mappingwhat do we map nowadays? Front Psychiatry 6:89, 2015

14. Parent A: Berengario da Carpi and the renaissance of brain anatomy. Front Neuroanat 13:11, 2019

15. Petrioli G: Riflessioni Anatomiche. Rome: Zempel, 1746

16. Sadikot AF, Chakravarty MM, Bertrand G, Rymar VV, AlSubaie F, Collins DL: Creation of computerized 3D MRIintegrated atlases of the human basal ganglia and thalamus. Front Syst Neurosci 5:71, 2011

17. Schaltenbrand G, Wahren W: Atlas for Stereotaxy of the Human Brain. Stuttgart: Thieme, 1977

18. Steinberg DA: Cerebral localization in the nineteenth century - the birth of a science and its modern consequences. $\mathbf{J}$ Hist Neurosci 18:254-261, 2009

19. Triarhou LC, Verina T: The musical centers of the brain: Vladimir E. Larionov (1857-1929) and the functional neuroanatomy of auditory perception. J Chem Neuroanat 77:143-160, 2016
20. Vesalius A: De Humani Corporis Fabrica Libri Septem. Basel: Ioannis Oporini, 1538

\section{Disclosures}

The authors report no conflict of interest concerning the materials or methods used in this study or the findings specified in this paper.

\section{Author Contributions}

Conception and design: all authors. Acquisition of data: Dario, Armocida. Drafting the article: Armocida. Critically revising the article: Dario, Locatelli. Reviewed submitted version of manuscript: Armocida.

\section{Supplemental Information \\ Previous Presentations}

Portions of this work were presented in abstract form as proceedings at the XIXth European Society for Stereotactic and Functional Neurosurgery (ESSFN) Congress, Athens, Greece, September 22-25, 2010.

\section{Correspondence}

Alessandro Dario: ASST Settelaghi, Varese, Italy. dario.alessandro@virgilio.it. 